\title{
Nuevas posibilidades y recursos para la enseñanza de la expresión corporal en educación física: internet y los retos virales \\ New ways and resources for teaching body expression in physical education: internet and viral challenges \\ Alejandro Carriedo, Antonio Méndez-Giménez, Javier Fernández-Río, JoséA. Cecchini \\ Universidad de Oviedo (España)
}

\begin{abstract}
Resumen: Hace más de 350.000 años, el ser humano comenzó a expresar ideas, sentimientos y emociones a través de las posibilidades motrices de su cuerpo; por aquel entonces centradas en gestos, danzas y rituales religiosos. Si bien la expresión corporal comprende un abanico mucho más amplio de prácticas y modalidades, en los últimos años el ser humano ha adoptado nuevas formas de expresión vehiculadas a través de internet, popularizando y extendiendo, entre otros, los denominados retos virales por todo el mundo. La asignatura de Educación Física, que en las últimas décadas ha experimentado una revolución en términos didácticos y de otros bloques de contenido, debe mantenerse también actualizada en las distintas posibilidades de trabajo de la expresividad humana. Por lo tanto, el propósito de este trabajo es hacer una revisión de los recursos emergentes que internet aporta así como las posibilidades que subyacen en las redes sociales para abordar de forma novedosa algunos elementos de la expresión corporal en los centros educativos. Estas propuestas tecnológicas son populares, significativas y auténticas. Sin embargo, se apuntan sugerencias metodológicas al objeto de implementar estos recursos expresivos en el aula desde un punto de vista educativo.
\end{abstract}

Palabras clave: Expresividad; redes sociales; actividad física; aplicaciones prácticas; contexto educativo.

\begin{abstract}
Human beings began expressing ideas, feelings, and emotions through their bodies' motor abilities more than 350.000 years ago. In the beginning, they did it through gestures, dances and religious rituals. Nowadays there is a much wider range of practices, and in the last years people have started expressing themselves through internet with challenges and viral trends. Physical education, which has experienced important didactic and content changes, must be updated with the different strategies to work on human expressiveness. Therefore, the aim of this paper is to review new resources taken from the internet and potential approaches within the social medias to address expressiveness in schools in an innovative way. These emerging proposals are popular, meaningful, and authentic. Nevertheless, methodological suggestions are included in order to implement these expressive resources in the classroom from an educational point of view.
\end{abstract}

Keywords: Expressiveness; social media; physical activity; practical applications; educative context.

\section{Introducción}

Se puede entender el origen de la expresión corporal cuando el ser humano comenzó a explorar las capacidades expresivas de su cuerpo y del movimiento. Fue en ese momento cuando imaginamos a un grupo de hombres y mujeres prehistóricos reunidos en torno al descubrimiento que cambiaría sus vidas para siempre: el fuego. El control del fuego, logrado al menos hace 350.000 años (Shimelmitz, Kuhn, Jelinek, Ronen, Clark \& Weinstein-Evron, 2014), no solo permitió ahuyentar a las fieras o cocinar alimentos; esta fuente de calor también facilitó que pequeños colectivos se reunieran en torno a él (Gowlett, 2016). Así, es probable que esta incipiente función social contribuyera al desarrollo del lenguaje (Gowlett, 2016), cuyo umbral parece encontrarse en los gestos expresivos que realizaban los primeros homínidos (Skoyles, 2000). De modo que, probablemente a partir de ese instante primigenio, se empezara a emplear el movimiento para algo más que para procurarse comida, defenderse o desplazarse. Irrumpía así la expresividad del cuerpo a través del movimiento.

Unos 350.000 años después, la expresión corporal ha evolucionado en sus formas y canales (Marañón, 2012; Motos, 1983; Rial \& Villanueva, 2016; Subires, 2012), hasta el punto que en los últimos años el ser humano ha comenzado a expresarse a través de internet, popularizando y extendien-

Fecha recepción: 12-12-18. Fecha de aceptación: 19-08-19 Alejandro Carriedo

carriedoalejandro@uniovi.es do los denominados retos o desafíos virales por todo el mundo (Sotoca, Arévalo \& Álvarez, 2017). Estas nuevas prácticas consisten en la realización de una tarea que puede suponer cierta complejidad en cuanto al mecanismo de ejecución, un indiscutible grado de valentía o arrojo (e.g., el reto de tirarse un cubo de agua helada por encima) o, simplemente, demostrar gestos divertidos que se hayan popularizado por diversas razones (e.g., porque lo ha hecho algún famoso). Una vez realizado, el desafío se graba con los teléfonos móviles y se publica en las redes sociales, a la vez que se anima o se «reta» a otros usuarios a hacer lo propio (e.g., M.S \& M.P, 2017, 7 de diciembre). Es por tanto, una nueva forma de expresión amplificada por la red, especialmente popular y significativa entre niños y jóvenes.

La expresión corporal es considerada un contenido fundamental del currículo de cualquier etapa educativa. Así, todo el alumnado de Educación Física, desde la etapa de infantil a bachillerato, debe desarrollar sus capacidades físicas artístico-expresivas mediante la experimentación de diferentes tipos de lenguaje para expresar su mundo emocional (García, Pérez \& Calvo, 2013; Padial-Ruz, Ibañez-Granados, Fernández \& Ubago-Jiménez, 2019; Peña \& Nicolás, 2019). Nos referimos al lenguaje musical, al lenguaje plástico, al lenguaje verbal y no verbal y al lenguaje corporal; y por este motivo, los docentes deben aprender a gestionar en sus aulas las emociones y habilidades sociales de su alumnado (Cruz, 2014). En este sentido, los Reales Decretos que regulan el proceso educativo en nuestro país se hacen eco de estas necesidades en las diferentes etapas educativas no universitarias, $\mathrm{y}$ señalan la importancia que subyace en el desarrollo de dife- 
rentes procedimientos afectivos, sociales, actitudinales, emotivos y sentimentales que pueden asociarse a la conducta motora, utilizando diversos medios de expresión y representación, así como el desarrollo de habilidades transversales como por ejemplo, el trabajo en equipo (i.e., Real Decreto $1630 / 2006$, de 29 de diciembre, por el que se establecen las enseñanzas mínimas del segundo ciclo de educación infantil; Real Decreto 126/2014, de 28 de febrero, por el que se establece el currículo básico de la Educación Primaria; Real Decreto 1105/2014, de 26 de diciembre, por el que se establece el currículo básico de la Educación Secundaria Obligatoria y del Bachillerato).

El movimiento y las manifestaciones de la comunicación son elementos clave para el desarrollo integral de los niños y niñas en edad escolar, y la expresión corporal se ocupa de la unión de estos dos elementos para educar en distintos aspectos. Así, Méndez-Giménez y Martínez (2017) concluyeron que la expresión corporal se considera un contenido eficaz para desarrollar la competencia emocional y social, la creatividad motriz o el pensamiento divergente entre el alumnado, lo que conlleva un bienestar psicofísico-emotivo. A través de esta forma de comunicación, el alumnado puede percibirse, conocerse y manifestarse; lo que a su vez, constituirá la base de otros aprendizajes específicos.

\section{La Expresión Corporal en Educación Física}

Carriedo (2017) apunta que la Educación Física podría sentirse orgullosa de ser una de las áreas/materias con más posibilidades para contribuir al desarrollo integral de los estudiantes, pues no solo incide positivamente en el ámbito físico, sino que múltiples investigaciones abalan sus posibilidades para favorecer el desarrollo emocional (Romero-Martín, Gelpi, Mateu \& Lavega, 2017), cognitivo y social de los más jóvenes (Brown, Pearson, Braithwaite, Brown \& Biddle, 2013; Janssen \& Leblanc, 2010). Esto es debido a que la actividad física se relaciona positivamente con aspectos tan relevantes para el desarrollo personal del alumnado como son la salud mental (Penedo \& Dahn, 2005), el autoconcepto (Carriedo, González \& López, 2013), el rendimiento académico (Cecchini \& Carriedo, 2019; Gómez-Pinilla, Vaynman \& Ying, 2008; Singh, Uijtdewilligen, Twisk, Van Mechelen \& Chinapaw, 2012), o con una menor probabilidad de padecer obesidad y enfermedades cardiovasculares (Janssen \& Leblanc, 2010; Strong, Malina, Blimke, Daniels, Dishman, Gutin, et al., 2005), entre otros. Para conseguir estos beneficios, la Educación Física dispone de múltiples contenidos como los juegos y deportes, las actividades físicas en el medio natural, las actividades físico-saludables, y las actividades físicas artístico-expresivas. En este sentido, la expresión corporal es un bloque de contenido presente en todos los currículos autonómicos. Sin embargo, no parece tener mucha popularidad entre el profesorado de Educación Física en las etapas de educación primaria y secundaria, y suele ser el bloque de contenidos menos valorado (Matanin \& Collier, 2003; Méndez-Alonso, Fernández-Río, Méndez-Giménez \& Prieto, 2015; Montávez, 2012; Robles, Abad, Castillo, Giménez \& Robles, 2013). Como resultado, los estudiantes de estas etapas informan de escasas experiencias de expresión corporal (Robles, 2008) y manifiestan actitudes negativas hacia este contenido (Robles, et al., 2013). Según Moreno y Hellín (2007) esto podría deberse a la escasa frecuencia con la que el profesorado lo imparte; así como a las lagunas en relación al enfoque metodológico empleado.

Para tratar de entender esta tendencia, varios trabajos han analizado los factores que condicionan la presencia de la expresión corporal en el aula (e.g., Méndez-Alonso, et al., 2015; Robles, et al., 2013), llegando a la conclusión de que el profesorado no está satisfecho con la formación inicial recibida durante los estudios de grado o diplomatura y que su formación continuada es precaria. Consecuentemente, no es extraño que este sea el bloque menos valorado por ellos, y, por lo tanto, poco demandado por sus alumnos, lo que alimenta un círculo vicioso que es necesario desenmarañar (Figura 1).

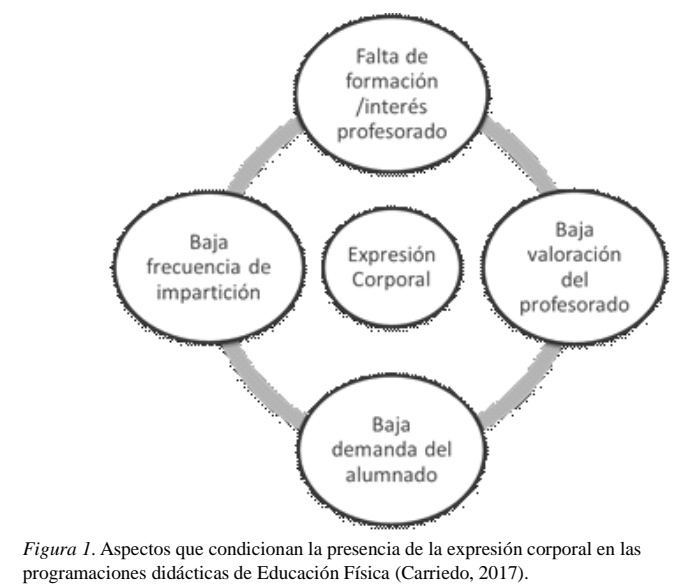

programaciones didácticas de Educación Física (Carriedo, 2017).

Tradicionalmente, la enseñanza de la expresión corporal estaba dirigida especialmente a las chicas y constreñida a la danza y a las gimnasias rítmicas (Vázquez, 1989). Tras introducirse formalmente en el currículo en todas las etapas, su papel cobró mayor relevancia (Arteaga, 2003). En este sentido, García, Pérez y Calvo (2013) señalan que para optimizar los beneficios de esta disciplina es necesario utilizar una metodología de enseñanza que promueva aprendizajes vivenciales o experienciales. Así, la finalidad educativa de la expresión corporal suele residir en el proceso per se que se propone para aprender (García, Pérez \& Calvo, 2013). En el contexto de la Educación Física se pueden trabajar todos los tipos de expresión (e.g., corporal, vocal, musical, coreográfica, gráfica/plástica), y para ello se suelen utilizar contenidos y recursos como el gesto, el movimiento expresivo del cuerpo, la postura, la mirada, la danza, los bailes, los juegos expresivos y cantados, el mimo o la expresión dramática (Herranz \& López, 2014; Villada \& Vizuete, 2002). Sin embargo, además de las formas expresivas tradicionales, los contenidos novedosos pueden ejercer un papel motivador clave y despertar el interés del alumnado y profesorado (Carriedo, 2015; González-Cutre, Sicilia, Sierra, Ferriz \& Hagger, 2016; Robles, Fuentes-Guerra, \& Abad, 2010). Desde un paradigma innovador, una opción puede ser enseñar contenidos tradicionales mediante un enfoque metodológico o modelo pedagógico novedoso (Fernández-Río, Hortigüela \& Pérez-Pueyo, 2018; Méndez-Giménez \& Martínez, 2017). Otra posibilidad es centrarse en la búsqueda de nuevos contenidos a impartir. En este sentido, las tecnologías de la información y de la comunicación (TIC) pueden ofrecernos multitud de recur- 
sos relacionados con la expresión corporal, que atraen la atención de niños y adolescentes y conectan con sus intereses y motivaciones.

Así, una característica inherente a los contenidos que se proponen en este trabajo hace referencia a la utilización de los teléfonos móviles en el aula, lo que se conoce como aprendizaje móvil o mobile learning (Aznar, Cáceres, Trujillo \& Romero, 2019). Esta orientación, más cuestionable en las etapas de educación infantil y primaria, podría ser considerada en etapas superiores, puesto que los estudiantes de secundaria y bachillerato suelen poseer sus propios smartphones (el 75,1\% de los jóvenes de 12 años, y el 94,8\% de los mayores de 15 años tiene uno: INE España, 2018). Algunos autores han señalado que pueden ser una fuente de distracción (Burns \& Lohenry, 2010), pero no podemos obviar las múltiples posibilidades que nos ofrece (e.g., realizar y editar fotografías y vídeos en alta calidad, de reproducir música, de descargar aplicaciones para realizar montajes y añadir efectos especiales a dichas grabaciones, buscar información en internet y en las redes sociales). Todas estas características hacen de los móviles e internet, herramientas muy atractivas para el desarrollo de los contenidos que se proponen en este trabajo. No debemos olvidar que los adolescentes son «nativos digitales» (Prensky, 2001), que en general están deseosos de utilizar sus teléfonos móviles en el aula para enseñar al mundo lo que son capaces de hacer. Esta motivación puede ser reconducida con la propuesta de tareas de competencia digital que pretenden traer al aula lo que los estudiantes aprenden fuera. La dimensión auténtica y significativa de dichas propuestas facilita que los estudiantes se involucren activamente en su aprendizaje (Engel \& Green, 2011).

Por lo tanto, el objetivo de este trabajo es hacer una revisión de actividades e iniciativas expresivas procedentes de internet y de los denominados retos virales así como de las posibilidades que subyacen en las redes sociales para ofrecer al profesorado de Educación Física recursos útiles e innovadores que les permita trabajar algunos elementos de la expresión corporal a través del movimiento y de la gamificación. Para la realización de la búsqueda se han establecido tres criterios: a) que la ejecución de los retos tenga relación con alguno de los componentes de la expresión corporal y del movimiento (e.g., el gesto, el mimo, el ritmo, bailes, danzas, actitud tónico postural equilibradora, etc.); b) que las actividades hayan generado interés en las redes sociales, y por ende que puedan despertar la motivación de nuestro alumnado; y c) que no supongan ningún tipo de riesgo para la salud individual o colectiva.

\section{Recursos de Expresión Corporal surgidos en Internet}

Comenzamos este recorrido destacando el papel de la música por ser un elemento clave para la expresividad, y por encontrarse indisolublemente unida al movimiento. Así, cuando escuchamos una melodía rítmica, involuntariamente tendemos a seguir su ritmo con un pie, las manos o la cabeza. La unión entre música y movimiento suponen un medio de expresión idóneo. Algunas de las propuestas más utilizadas en Educación Física parten de esa alianza de ambos elementos; por ejemplo, las coreografías o composiciones grupales, el acrosport, la gimnasia rítmica, o los contenidos procedentes de los gimnasios como el aerobic, la batuka o el bodycombat. Dentro de este ámbito, encontramos en el flashmob y en el lipdub las propuestas más novedosas (Fernández-Bustos, Méndez-Giménez \& Sánchez-Gómez, 2018) que se están difundiendo rápidamente gracias a internet y las redes sociales.

\section{Flashmob}

Flashmob es un término que hace referencia a una nueva clase de expresión social colectiva realizada bajo una falsa espontaneidad en lugares públicos. Consiste en realizar una representación breve y enérgica que causa sorpresa a los espectadores y que puede difundirse rápidamente gracias a las TIC e internet. Se considera a Bill Wasik como el padre de esta práctica cuando coordinó el primer flashmob en el año 2003 en la ciudad de Nueva York. Wasik definió esta actividad como una reunión pública de personas desconocidas entre sí, las cuales se organizan a través de internet o del teléfono móvil para realizar un acto sin sentido y dispersarse a continuación (Marcillas, 2013). Para elaborar un flashmob se puede hacer un baile, un concierto o una representación teatral donde parece que las personas del público se unen y se disuelven de manera espontánea y natural (Carriedo, 2017). Aunque su naturaleza propia requiere una ejecución en espacios públicos, también puede ser desarrollado en el patio del centro educativo o en sus alrededores.

\section{Lipdub}

El Lipdub es una práctica audiovisual que recientemente está adquiriendo mucha presencia en escuelas, institutos y facultades universitarias. Subires (2012) lo define como un videoclip colaborativo en el que un grupo de personas crean una escenografía y la representan mientras hacen playback con una o varias canciones. Para ello, deben sincronizar sus labios, sus gestos y sus movimientos. Se considera que debe realizarse en una única toma y con un único plano. Para ello, una persona empezaría a grabar mientras se desplaza por un recorrido previamente organizado en el que los participantes van apareciendo «espontáneamente» para realizar diferentes gestos, bailes o movimientos. Si recordamos el videoclip Wannabe que las Spice Girls lanzaron en 1996, podremos ver que las características propias del lipdub se cumplen, por lo que es considerado como el primero de la historia. No obstante, no fue hasta el año 2006 que Jakob Lodwick acuñó el término después de difundir un vídeo de estas características en una red social (Marañón, 2012). Esta propuesta podría enmarcarse en un proyecto en el que colabore un grupo, un nivel educativo o el centro completo. El proceso de creación es el fin en sí mismo, pero el producto (i.e., el resultado final) conlleva altos índices de satisfacción personal para quien participa en él; enriqueciendo además, el plano cognitivo, motriz, y afectivo-social (Gómez, de la Orden \& Cuellar, 2012). Para realizar un lipdub se debe pasar por varias fases: a) Fase de planificación: elegir la música adecuada (tiene que ser dinámica y alegre), organizar el recorrido y pedir los permisos necesarios si va a hacerse en el centro, planificar la actuación de cada grupo o persona, determinar el espacio que ocupará cada grupo o persona y el momento de actuación; b) Fase de ensayo: una vez planificado, el 
lipdub debe repetirse varias veces hasta que esté totalmente sincronizado; c) Fase de grabación: El lipdub se registra en una sola toma y sin cortes, por lo que la grabación final será la puesta en escena en el que tendrán que estar listos todos los decorados y el vestuario. A pesar de los ensayos, al ser grabado en una única toma, puede dar lugar a la improvisación. Los posibles errores que pudieran surgir por los nervios del directo pueden ser «tapados» con la improvisación.

\section{Recursos Emergentes derivados de laAdaptación Edu- cativa de los Retos Virales}

En el verano de 2014, un movimiento de concienciación y de solarización con los enfermos de esclerosis lateral amiotrófica impulsó una campaña para recaudar fondos para la investigación de esta enfermedad bajo el lema de \#icecubechallenge o reto del cubo de agua helada. Este reto viral, que consistía en echarse agua helada por encima y, posteriormente, publicar el vídeo en las redes sociales a la vez que se retaba a varias personas a que lo repitiesen, se popularizó rápidamente por todo el mundo gracias a la colaboración de personajes famosos. Desde entonces, diversos retos virales han sido difundidos por internet y podrían ser adaptados fácilmente para trabajar algunos elementos de la expresión corporal en nuestras clases de Educación Física. Para ello, se debería conservar la mayor parte de las características originales del desafío (Sotoca, Arévalo \& Álvarez, 2017). Al mismo tiempo, sería interesante tratar de vincular estos retos con valores educativos y no solamente con modas y la emulación de personajes famosos. Aunque la mayoría de estos recursos serían más adecuados para el alumnado de los últimos cursos de Educación Secundaria y Bachillerato, también es cierto que podrían ser adaptados en las etapas inferiores reduciendo la complejidad de ejecución de algunos movimientos y eliminando los aspectos más relacionados con las redes sociales. A continuación, se muestran algunos ejemplos y posibilidades.

\section{\#Mannequinchallenge}

El mannequin challenge, o el reto del maniquí, es un fenómeno surgido de internet en el que los participantes deben adoptar una postura completamente estática que refleje algún tipo de movimiento. Es una actividad que debe hacerse en grupo (cuantas más personas participen, más espectacular resulta) y un miembro externo debe realizar una grabación de la composición grupal en la que se vean diferentes detalles de las posturas de los maniquíes: debe ser una grabación dinámica que vendría a representar una especie de fotografía en tres dimensiones. Esta práctica, que se hizo fugazmente visible en las redes sociales de distintos personajes famosos, también irrumpió con fuerza en los centros educativos y provocó buenos resultados en cuanto a motivación e interés por parte del alumnado (pueden verse numerosos ejemplos en www.youtube.com). Puede ser una actividad interesante para romper el hielo al inicio del curso, aunque un grupo bien cohesionado probablemente será capaz de crear un producto más armonioso y visual. Por este motivo, este desafío podría repetirse una vez haya avanzado el curso y se haya trabajado la cohesión grupal (véase el apartado de sugerencias metodológicas). Consideramos im- portante que en un primer momento los estudiantes decidan libre y de forma creativa la posición que van a mantener durante la grabación, y aunque se recomienda que participe todo el alumnado, los estudiantes más tímidos podrían ser los encargados de grabar las imágenes. En edades más avanzadas se podría proponer la elaboración de un producto relacionado con valores socioeducativos, como por ejemplo que el alumnado de bachillerato cree y difunda un mannequinchallenge que enviase un mensaje de concienciación medioambiental o que fomente un estilo de vida activo.

\section{\#Andy'scoming}

El Andy's coming es un reto posterior al manequin challenge cuya idea fue obtenida de la película Toy Story (Lasseter, 1995). El desafío hace alusión a una escena en la que los muñecos están interactuando y rápidamente deben hacerse los «muñecos» porque Andy, el niño de la casa, está a punto de entrar en su habitación. En nuestras clases consistiría en representar exactamente lo mismo. El alumnado estaría haciendo una actividad motriz cualquiera, y en el momento en el que el docente grita «jahí viene Andy!» todos deben tirarse al suelo como si fueran muñecos inmóviles (Figura 2). El control de la postura y del tono muscular es clave en esta práctica porque de una fase de activación y tensión, el alumnado debe rápidamente establecer una activación y un tono prácticamente nulos. Este desafío debería realizarse en terrenos blandos. Asimismo, en los cursos de educación infantil y primaria los estudiantes deberían mantener cierto margen de separación entre ellos para evitar encontronazos. Una vez hecha la grabación, se podría editar el vídeo incluyendo la voz original de la película o añadiendo a algunos de los muñecos en el montaje.

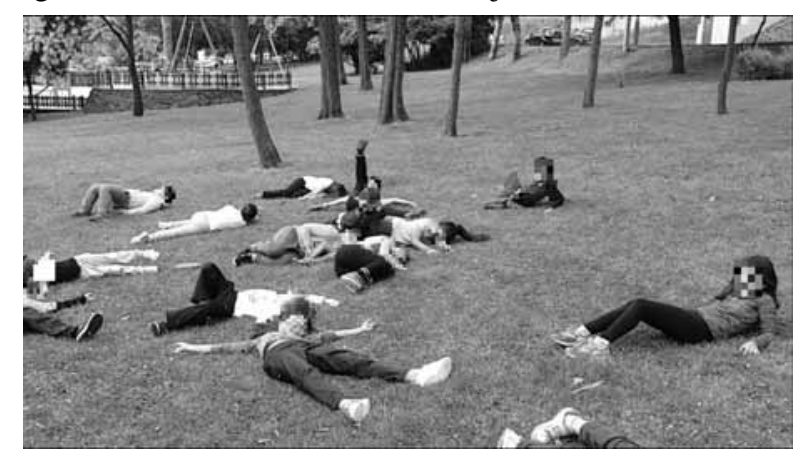

Figura 2. Alumnado de $2^{\circ}$ curso de Educación primaria realizando el reto de Andy's coming.

\section{\#Trumpiscoming}

Traducido como ¡Ahí viene Trump! podría considerarse una evolución del Andy's Coming porque se trata de un reto en el que los participantes están haciendo una actividad cualquiera y en el momento en que alguien grita ¡que viene Trump! todos deben salir huyendo del polémico magnate, que dos meses después del inicio de este viral se convertiría en el $45^{\circ}$ presidente de los Estados Unidos de América. A diferencia del reto anterior, los participantes tienen que mantener un tono muscular de acción durante la actividad que estén realizando (sea dinámica o no) para que en el menor tiempo posible puedan contraer toda su musculatura para salir corriendo y esconderse del campo de visión de la cámara que esté grabando el desafío. Dado el carácter explosivo del movimiento que provoca el aviso de la llegada de Trump, 
esta actividad debería realizarse después de haber hecho un buen calentamiento.

\section{\#Thefloorislavachallenge}

The floor is lava challenge o el reto del suelo es lava es otro de los retos procedentes de las modas virales de internet. En esta ocasión, el alumnado está realizando cualquier actividad en cualquier lugar y en el momento en el que se escucha la frase «el suelo es lava» tienen que ponerse a salvo colocándose en un sitio elevado (e.g., un banco, una colchoneta, una espaldera...). Posteriormente, se edita la fotografía o el vídeo añadiendo efectos de lava por el suelo y se cuelga en las redes sociales (pueden verse múltiples ejemplos en www.youtube.com). Este reto es muy sencillo de aplicar en la escuela, y en realidad podríamos decir que es una forma gamificada de un conocido juego en el que el alumnado tiene que obedecer rápidamente las órdenes del profesor (e.g., subirse a las espalderas, subirse a un alto, poner los pies en el aire, etc.). De modo que lo realmente novedoso de este desafío residiría en la edición de las imágenes, por lo que tan solo se tendrían que tener en cuenta las recomendaciones sobre el uso del teléfono móvil en el aula (véase el apartado de sugerencias metodológicas).

\section{\#Invisibleboxchallenge}

El reto del cajón invisible tiene cierta complicación coordinativa y se enmarcaría en el ámbito del mimo. Este reto fue iniciado por Dontez Hines, un jugador de fútbol americano de la Universidad de Anderson, Indiana, cuando en agosto de 2017 publicó un vídeo en las redes sociales en el que primero «tocaba» con la palma de la mano un cajón invisible y después lo «pisaba» con un pie mientras pasaba el otro pie por encima de la «caja» (puede verse el vídeo en la cuenta oficial de Twiter de Dontez Hines: @thecvmevp). Es decir, consiste en simular pisar un cajón invisible, lo que supone representar el efecto de una presión de fuerza sobre el aire para crear la ilusión de que se ha pisado el cajón. Para ello, se debe saltar con un pie mientras que el otro (el que simula estar sobre el cajón) permanece lo más firme y estable posible. Es un desafío bastante complejo que podría presentarse al alumnado del último curso de secundaria o de bachillerato, porque requiere elevados niveles de coordinación, fuerza y equilibrio. De hecho, cuando Dontez retó a sus seguidores a repetirlo, la primera reacción de los internautas fue de incredulidad, tachando el reto de fraude, y no se popularizó hasta que Ariel Olivar, una animadora del Instituto Mangel, consiguió hacer correctamente el desafío en diciembre del mismo año (M.S \& M.P, 2017, 7 de diciembre). La joven se hizo rápidamente famosa en internet y en los medios de comunicación cuando demostró que el vídeo no había sido manipulado; lo que instantáneamente animó al resto de usuarios de las redes sociales a intentar repetir esta hazaña tan visual. Es desafío podría motivar a muchos de nuestros alumnos a tratar de conseguir el reto y demostrar que son capaces de realizar un movimiento muy complejo a nivel coordinativo. Por este motivo, podría ser interesante introducir el reto en clase y proponer al alumnado que practique fuera de las horas de educación física. De esta manera también estaríamos incentivando la realización actividad física fuera de la escuela.

\section{\#DeleAlliChallenge}

El reto de Dele Alli es uno de los últimos retos virales y comenzó a popularizarse a principios de 2018. Este desafío fue popularizado por el futbolista Dele Alli a través de las redes sociales y puede ubicarse dentro del gesto como contenido expresivo. Este jugador del Tottenham ha generado un enorme interés entre los más jóvenes, quienes tras observar la particular forma en que este jugador celebró uno de sus goles, se lanzaron en masa a tratar de repetir es gesto extraño y difícil de lograr (Figura 3). Denominaron a este nuevo desafío Dele Alli Challenge. Consiste en realizar un gesto con la mano para posteriormente apoyarla sobre la cara, dejando un ojo entre los dedos índice y pulgar. Este desafío podría utilizarse para introducir el gesto como un elemento fundamental del lenguaje corporal.

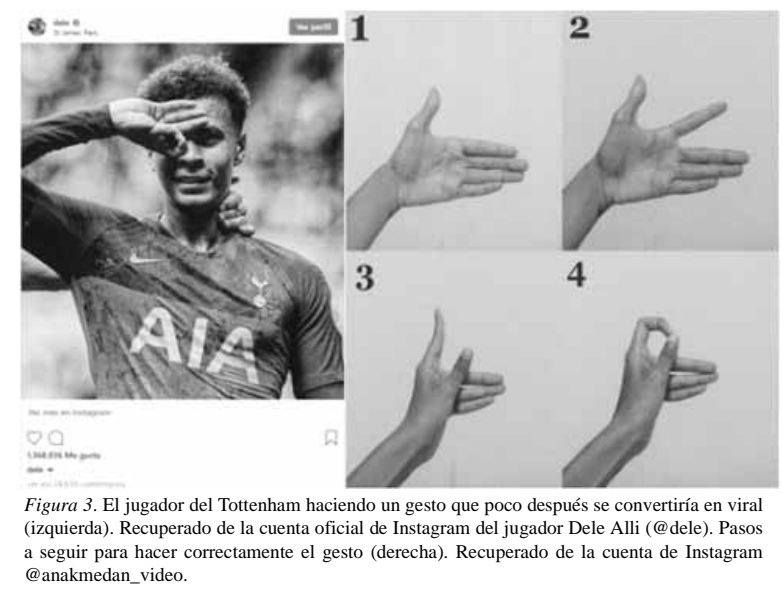

\section{\#Inmyfeellingschallenge}

Continuamos con un reto ideado por Shiggy, un cómico estadounidense que dio nombre a uno de los últimos desafíos del año 2018. El denominado In my Feelings Challenge (por el nombre de la canción que se utiliza en el desafío) o el Shiggy Challenge. Consiste en hacer una divertida coreografía al ritmo de la canción In my feelings del rapero Drake. El cómico americano publicó en su cuenta de Instagram un vídeo haciendo, él mismo, un baile nocturno al ritmo de esta canción al borde de una carretera. Rápidamente famosos y demás usuarios de las redes sociales comenzaron a imitarle. Sin embargo, este reto fue evolucionando hacia una forma de bailar en distintas ubicaciones peligrosas, como en carreteras abiertas o al lado de un coche en movimiento, lo que ya se ha cobrado algún que otro accidente. En el contexto educativo, este reto requiere una sensibilización sobre los riesgos que suponen ciertas conductas y podría realizarse simplemente imitando la secuencia rítmica creada por el cómico, lo que no dejaría de ser una coreografía, pero contextualizada bajo el paraguas de una moda viral. De tal modo que este desafío podría tener dos fases, una en la que el alumnado imite esta coreografía viral, y otra en la que los estudiantes creen una coreografía propia para que posteriormente pueda ser imitada por otros estudiantes. Estos desafíos podrían hacerse a nivel intragrupal (i.e., dentro de la misma clase alumnos que desafían a otros compañeros) o intergrupal (i.e., una clase desafía a otra o un centro educativo desafía a otro). 


\section{\#AryaChallenge}

Finalizamos este recorrido de retos virales susceptibles de ser utilizados en las clases de Educación Física aprovechando el tirón mediático de la popular serie de televisión Juego de Tronos. Así, podemos sugerir a nuestro alumnado que trate de imitar un gesto con el que un importante personaje de esta ficción consiguió vencer a un terrible enemigo en uno de los últimos capítulos de la serie. Tras la emisión del episodio, en mayo de 2019, los usuarios de las redes sociales comenzaron a compartir sus intentos para reproducir dicho movimiento, el cual requiere de un alto grado de coordinación y de percepción temporal. Aunque la protagonista usa una daga, el desafío podría realizarse con cualquier objeto, como un peine, un micrófono, o una pica. Como se propuso con el reto del cajón invisible, el alumnado podría sentirse motivado a conseguir este desafío en el periodo extraescolar.

\section{Sugerencias Metodológicas}

Para implementar con éxito estos recursos se incluyen una serie de sugerencias metodológicas comunes a la realización de cualquier actividad de índole cooperativo. En ese sentido, varios autores (Fernández-Río, 2017; Fernández-Río \& Méndez-Giménez, 2016; Fernández-Río, Hortigüela \& Pérez-Pueyo, 2018) han propuesto la creación de un ambiente adecuado y una serie de fases. Creemos que estas directrices son extrapolables, en nuestro caso, al trabajo grupal y cooperativo de los estudiantes en la elaboración de un lipdud o un flashmob.

En primer lugar, el docente debería promover la cohesión del grupo para que todos los integrantes fueran capaces de trabajar juntos, no solo con aquellos que comparten mayor afinidad o afecto. Para ello, se pueden plantear diferentes actividades de presentación, de rompehielos, de confianza, y de autoconocimiento (véase Fernández-Rio, 2017). En el desarrollo de estas actividades se podrían experimentar diversos tipos de agrupamientos para estrechar las relaciones y fortalecer las habilidades sociales (Fernández-Río, Hortigüela \& Pérez-Pueyo, 2018). Este proceso facilitará la cooperación, el funcionamiento y la organización en pequeño, pero también en gran grupo, que se requerirá posteriormente. En este sentido, no existe consenso sobre cómo se deben formar estos grupos. Velázquez (2013) plantea que pueden ser por azar, por conveniencia, elegidos por los estudiantes, o elegidos por el profesor. Fernández-Río, Hortigüela y Pérez-Pueyo (2018) señalan que cada una de estas posibilidades plantean aspectos positivos y negativos, y sugieren que los docentes con menos experiencia en el aprendizaje cooperativo se decanten por formar los grupos ellos mismos, aunque sin dejar de comprobar y analizar el funcionamiento del resto de opciones.

Las siguientes sugerencias hacen alusión al comportamiento del docente y al uso o no de la competición (Fernández-Rio, Hortigüela \& Pérez-Pueyo, 2018). Ambos aspectos guardan relación con el lenguaje usado por el docente o con la organización de las tareas al objeto de fortalecer un clima en el que se prime el proceso y el logro colectivo frente a los éxitos individuales. Crear un adecuado clima que favorezca el trabajo cooperativo puede llevar más tiempo en determinados grupos, por lo que el docente deberá observar el comportamiento del alumnado e ir avanzando en las diferentes fases según se vayan cumpliendo los objetivos de cada fase.

Asimismo, estas prácticas colectivas de expresión pueden ubicarse dentro de un aprendizaje basado en proyectos (e.g., Archilla-Prat \& Pérez-Brunicardi, 2017; Rial \& Villanueva, 2016) en el que se sume el uso de las TIC y las redes sociales como herramientas de investigación, comunicación y difusión. En consecuencia, esta metodología de trabajo se verá favorecida si antes se ha conseguido formar un verdadero grupo cooperativo que facilite el desarrollo de un aprendizaje activo.

La utilización de los teléfonos móviles en el aula ha provocado un debate en curso respecto a su uso en los centros educativos (Jackson, 2012). Engel y Green (2011) apuntan que principalmente se han usado de tres maneras: 1) como un sistema de respuesta inmediata; 2) como una herramienta de investigación; 3) como una herramienta para recoger evidencias del trabajo de los estudiantes mediante fotografías o vídeos. En nuestro caso, esta herramienta tecnológica nos brinda la posibilidad de realizar y editar fotografías y vídeos en alta calidad, de reproducir música, de descargar aplicaciones para realizar montajes y añadir efectos especiales a dichas grabaciones. Además, permite obtener un feedback inmediato tras la realización de un movimiento, gesto, baile o figura, y facilita la visualización de grabaciones y productos elaborados por estudiantes de otros centros educativos para obtener ideas. Es decir, también facilita la búsqueda de información en internet y en las redes sociales. Así, además de favorecer la creación de un producto de calidad, otra posibilidad podría ser que el docente proponga a su alumnado la invención y ejecución de diferentes desafíos, para que posteriormente puedan retar en las redes sociales a sus amigos y conocidos a realizar distintas actividades que promuevan actitudes de vida saludable (e.g., hacer una ruta de senderismo con sus padres, no fumar durante un mes o más tiempo, no consumir bebidas alcohólicas, etc.). Es importante que estos desafíos estén supervisados y aprobados por el profesorado antes de que los estudiantes se animen a difundirlos.

A pesar de estas expectativas, existen potenciales amenazas en torno al mal uso del teléfono móvil y de las redes sociales en las escuelas, por lo que se hace imprescindible establecer una serie de medidas que garanticen la seguridad y la privacidad de los estudiantes. Algunas de las sugerencias que abordamos a continuación están basadas en las propuestas hechas por Engel y Green (2011) y en la guía práctica para introducir dispositivos móviles en el aula que elaboraron en el Colexio Juventud de Santiago de Compostela (2014): a) adoptar medidas para evitar publicaciones negativas sobre compañeros de clase y/o docentes, el ciberbullyng o ciberacoso; b) definir claramente los objetivos de aprendizaje que se pretenden conseguir con la actividad; c) concienciar a los estudiantes sobre el efecto negativo de distraerse con el uso del teléfono móvil en clase, d) hacer una selección del dispositivo o del número de dispositivos a utilizar por cada grupo; e) definir el tiempo de uso y concretar las acciones curriculares; f) determinar el acceso a internet (necesario o no necesario); g) delimitar el uso en el 
aula y la participación de los estudiantes, así como asignar los diferentes roles dentro del grupo (cuándo, cómo, qué y quién); h) acordar alternativas en caso de no disponer de suficientes dispositivos, o del permiso de las familias para que se use el móvil en el aula; i) establecer pautas (comunes o no comunes) en la selección y utilización de las diferentes aplicaciones que pueden utilizarse para grabar, editar o crear efectos especiales (e.g., añadir lava, rótulos, emoticonos o diversos efectos como por ejemplo el stopmotion); j) determinar si los participantes dan su consentimiento para que el producto final sea publicado y difundido en las redes sociales (una alternativa sería crear un canal o un medio privado en el que solo los miembros del grupo tengan acceso a él); $y$, finalmente, k) actuar con mucha cautela a la hora de utilizar estos nuevos recursos frente a la moda de ciertos retos virales peligrosos y alejados de las intenciones pedagógicas. Se trata, pues, de concienciar al alumnado de que algunos de estos nuevos desafíos conllevan serios riesgos para la salud (e.g., el reto de tragarse una cucharada de sal y canela, el reto de echarse agua hirviendo por encima o bebérsela, el reto de la ballena azul, el reto de ponerse hielo y sal en la piel porque produce una reacción química que causa quemaduras en la piel, etc.). De hecho, sería muy recomendable aprovechar esta moda para abordar los riesgos que subyacen en la práctica de actividad física sin la supervisión de un profesional. Este aspecto se hace sumamente importante debido a que el alumnado podría llegar a retarse a realizar actividades peligrosas para su salud. Por ejemplo, recientemente dos adolescentes chinas se desafiaron a través de las redes sociales a hacer mil sentadillas, resultando en el ingreso hospitalario de ambas (Amores, 2019, 1 de agosto).

En definitiva, el docente debe tomar conciencia de las posibilidades que le brindan las TIC, y a su vez, aprovechar estos contenidos para transmitir un mensaje crítico y reflexivo sobre la realización de las prácticas surgidas en internet, valorando los riesgos que puedan suponer, promoviendo debates y charlas de concienciación o posibilitando la creación de montajes de vídeo a modo de corto cinematográfico en los que el propio alumnado aborde esta temática.

El trabajo de la expresión corporal comprende un amplio abanico de aspectos que merecen ser trabajados con profundidad (e.g., el gesto, la voz, el dominio cinestésico para comunicar, para relacionarse, la interacción de las emociones...). La realización de un reto o desafío en el que el alumnado tenga que realizar un baile, una figura, un movimiento, o un gesto no es suficiente para desarrollar estos aspectos. Por lo tanto, recomendamos que estas propuestas sean utilizadas como reclamo o invitación para un trabajo posterior más exhaustivo de los elementos que componen la expresión corporal. Por lo tanto, el profesorado concienciado en la importancia de la enseñanza de la expresión corporal en la escuela debería utilizar estos recursos como una idea que promueva nuevas posibilidades de actuación. Sobre todo, teniendo en cuenta la naturaleza fugaz de estas propuestas. Por ello, se recomienda que la formación recibida en los grados universitarios sea complementada con las lecturas y propuestas de referentes en este campo (e.g. Cañas, 2009; Motos, 1983; Tejerina, 1994), así como con la asistencia a cursos, talleres y congresos.

\section{Conclusiones}

La expresión corporal es un contenido que debe ser desarrollado en todas las etapas educativas. Para ello es importante conocer la forma tradicional de trabajarla, pero también las propuestas y recursos más innovadores. El objetivo de este trabajo es ofrecer al profesorado de Educación Física nuevas posibilidades para trabajar algunos elementos de la expresión corporal en sus clases así como las posibilidades que internet ofrece. La literatura señala que este contenido no es muy popular entre el alumnado y el profesorado. Sin embargo, la implementación de propuestas novedosas, significativas y auténticas podría ayudar a mejorar esta tendencia. Los teléfonos móviles actuales y el conocimiento que posee nuestro alumnado sobre el funcionamiento de las redes sociales permiten que la realización de estas actividades pueda ser editada y difundida posteriormente, lo que podría añadir un plus de motivación e interés entre el alumnado.

\section{Referencias}

Amores, D. (2019, 1 de agosto). Dos chicas acaban en la UCI tras practicar el reto de las 1.000 sentadillas. La voz de Galicia. Recuperado de https://www.lavozdegalicia.es/ noticia/sociedad/2019/08/01/dos-chicas-acaban-uci-trasp r a c t i c a r - r e t o- $1000-$ s e n t a d i lla s / 00031564672056868720114.htm

Archilla-Prat, M., \& Pérez Brunicardi, D. (2017). Las luces de la expresión corporal. Ventajas y posibilidades de los «Proyectos de Aprendizaje Expresivos» en Educación Física en Secundaria. Retos: Nuevas Tendencias en Educación Física, Deporte y Recreación, 31, 232-237.

Arteaga, M. (2003). Fundamentos de la expresión corporal: Ámbito pedagógico. Granada: Grupo editorial universitario.

Aznar, I., Cáceres, M.P., Trujillo, J.M., \& Romero, J.M. (2019). Impacto de las apps móviles en la actividad física: un meta-análisis. Retos: nuevas tendencias en educación física, deporte y recreación 36, 52-57.

Brown, H.E., Pearson, N., Braithwaite, R.E., Brown, W.J., \& Biddle, S.J. (2013). Physical activity interventions and depression in children and adolescents. Sports Medicine, 43(3), 195-206.

Burns, S.M., \& Lohenry, K. (2010). Cellular phone use in class: Implications for teaching and learning a pilot study. College Student Journal, 44(3), 805-810.

Cañas, J. (2009). Taller de juegos teatrales. Barcelona: Octaedro.

Carriedo, A. (2015). Metas de logro, diversión y persistenciaesfuerzo en estudiantes de educación física durante una unidad didáctica sobre judo. Magister, 27(2), 51-58.

Carriedo, A. (2017). Prácticas innovadoras e inclusivas para la enseñanza de la expresión corporal en Educación Física. En A. Rodríguez-Martín (Comp.) Prácticas innovadoras inclusivas retos y oportunidades (pp. 12511258). Oviedo: Universidad de Oviedo

Carriedo, A., González de Mesa, C., \& López, I. (2013). Relación entre la meta de logro en las clases de Educación Física y el autoconcepto de los adolescentes. Revista Española de Educación Física y Deportes, 403, 13-24. 
Cecchini, J.A., \& Carriedo, A. (2019). Effects of an interdisciplinary approach integrating mathematics and physical education on mathematical learning and physical activity levels. Journal of Teaching in Physical Education. Doi: https://doi.org/10.1123/jtpe.2018-0274

Colexio Juventud de Santiago de Compostela (2014). Guía práctica para introducir dispositivos móviles en el aula: la experiencia del Colexio Juventud. Recuperado de https://observatorio.profuturo.education/blog/2014/10/ 20/guia-practica-para-introducir-dispositivos-movilesen-el-aula-la-experiencia-del-colexio-juventud/

Cruz, P.C. (2014). Creatividad e Inteligencia Emocional. (Como desarrollar la competencia emocional, en Educación Infantil, a través de la expresión lingüística y corporal). Historia y comunicación social, 19, 107-118.

Engel, G., \& Green, T. (2011). Cell phones in the classroom: Are we dialing up disaster? TechTrends, 55(2), 39-45.

Fernández-Río, J. (2017). El Ciclo del Aprendizaje Cooperativo: una guía para implementar de manera efectiva el aprendizaje cooperativo en educación física. Retos: nuevas tendencias en educación física, deporte y recreación, 32, 264-269.

Fernández-Río, J., Hortigüela, D., \& Pérez-Pueyo, Á. (2018). Revisando los modelos pedagógicos en educación física. Ideas clave para incorporarlos al aula. Revista Española de Educación Física y Deportes, (423), 57-80.

Fernández-Río, J., \& Méndez-Giménez, A. (2016). El aprendizaje cooperativo: Modelo pedagógico para Educación Física. Retos: nuevas tendencias en educación física, deporte y recreación, 29, 201-206.

Fernández-Bustos, J.G, Méndez-Giménez, A., \& SánchezGómez, R. (2018). Didáctica de la Educación Física para Bachillerato basada en Modelos. Madrid: Ed. Síntesis.

García, I, Pérez, R., \& Calvo, Á. (2013). Expresión corporal. Una práctica de intervención que permite encontrar un lenguaje propio mediante el estudio y la profundización del empleo del cuerpo. Retos: nuevas tendencias en educación física, deporte y recreación, 23, 19-22.

Gómez, E., de la Orden, G., \& Cuellar, J. (2012). Realización de un lipdubpara la asignatura de expresión corporal. Diseño y realización de una experiencia para los maestros especialistas en educación física. EmásF Revista Digital de Educación Física, 16, 20-29.

Gómez-Pinilla, F., Vaynman, S., \& Ying, Z. (2008). Brain-derived neurotrophic factor functions as a metabotrophin to mediate the effects of exercise on cognition. European Journal of Neuroscience, 28(11), 2278-87.

González-Cutre, D., Sicilia, A., Sierra, A.C., Ferriz, R., \& Hagger, M.S. (2016). Understanding the need for novelty from the perspective of self-determination theory. Personality and Individual Differences, 102, 159-169.

Gowlett, J.A. (2016). The discovery of fire by humans: a long and convoluted process. Philosophical Transactions of the Royal Society B Sci, 371(1696), 20150164.

Herranz, A., \& López, V.M. (2015). La expresión corporal en Educación Infantil. La Peonza: Revista de Educación Física para la paz, 10, 23-44.

INE España. (2018). Encuesta sobre equipamiento y uso de tecnologías de información y comunicación en los hogares. Notas de prensa 7 de noviembre de 2018: Recupe- rado de https://www.ine.es/prensa/tich_2018.pdf

Jackson, L.D. (2012). Is Mobile Technology in the Classroom a Helpful Tool or a Distraction?: A Report of University Students' Attitudes, Usage Practices, and Suggestions for Policies. International Journal of Technology, Knowledge \& Society, 8(5).

Janssen, I., \& Leblanc, A.G. (2010). Systematic review of the health benefits of physical activity and fitness in schoolaged children and youth. International Journal of Behavioral Nutrition and Physical Activity, 7(40), 1-16.

Lasseter, J. (1995). Toy Story. Estados Unidos de America: Pixar Animation Studiosy Walt Disney Studios.

Marañón, C. (2012). Creatividad, publicidad y educación emocional: fundamentos del lipdub como aplicación de la imagen de la marca de las universidades. Arte y Sociedad. Revista de Investigación, 2, 11-17.

Marcillas, I. (2013). Flasmobs: la transformación de la dramaturgia a través de las redes sociales. En J. Romera (Ed.), Teatro e Internet en la primera década del siglo XXI(235-249). Madrid: Editorial Verbum.

Matanin, M., \& Collier, C. (2003). Longitudinal analysis of preservice teachers' beliefs about teaching physical education. Journal of Teaching in Physical Education, 22, 153-168.

Méndez-Alonso, D., Fernández-Río, J., Méndez-Giménez, A., \& Prieto, J. A. (2015). Estudio sobre las variables que influyen en el desarrollo de los contenidos en educación física en primaria en el Principado de Asturias, Retos: Nuevas Tendencias en Educación Física Deporte y Recreación 28, 104-109.

Méndez-Giménez, A., \& Martínez, D. (2017). Percepciones del estudiante de Primaria sobre el uso del modelo de educación deportiva para la enseñanza del mimo. Revista Española de Educación Física y Deportes, 418, 21-34.

Montávez, M. (2012). La expresión corporal en la realidad educativa. Descripción y análisis de su enseñanza como punto de referencia para la mejora de la calidad docente en los centros públicos de educación primaria de la ciudad de Córdoba (Tesis Doctoral no publicada) Universidad de Córdoba, España.

Moreno, J.A., \& Hellín, M.G. (2007). El interés del alumnado de Educación Secundaria Obligatoria hacia la Educación Física. Revista Electrónica de Investigación Educativa, 9(2).

Motos, T. (1983). Iniciación a la expresión corporal: teoría, técnica y práctica. Barcelona: Ed. Humanistas.

M.S., \& M.P. (2017, 7 de diciembre). «La caja invisible»: así es el nuevo reto viral. La voz de Galicia. Recuperado de https://www.lavozdegalicia.es/noticia/informacion/2017/ 12/07/the-invisible-box-nuevo-reto-viral/ 00031512661882905941530.htm

Padial-Ruz, R., Ibañez-Granados, D., Fernández, M., \& UbagoJiménez, J.L. (2019). Proyecto de baile flamenco: desarrollo motriz y emocional en educación infantil. Retos: nuevas tendencias en educación física, deporte y recreación, 35, 396-401.

Penedo F.J., \& Dahn J.R. (2005). Exercise and well-being: a review of mental and physical health benefits associated with physical activity. Current Opinion in Psychiatry, 18(2), 189-193. 
Peña, V.J., \& Nicolás, G.V.(2019). Danza en educación infantil: opinión de los docentes. Retos: nuevas tendencias en educación física, deporte y recreación, 36, 239-244.

Prensky, M. (2001). Digital natives, digital immigrants. On the Horizon, 9(5), 1-6.

Real Decreto 1105/2014, de 26 de diciembre, por el que se establece el currículo básico de la Educación Secundaria Obligatoria y del Bachillerato. BOE núm 3, 3 de enero de 2015.

Real Decreto 126/2014, de 28 de febrero, por el que se establece el currículo básico de la Educación Primaria. BOE núm 52, 1 de marzo de 2014.

Real Decreto 1630/2006, de 29 de diciembre, por el que se establecen las enseñanzas mínimas del segundo ciclo de educación infantil BOE núm 4, de 4 de enero de 2007.

Rial, T., \& Villanueva, C. (2016). El Flashmob como propuesta de innovación educativa en expresión corporal y danza. Retos: nuevas tendencias en Educación Física, deporte y recreación, 29, 126-128.

Robles, J. (2008). Causas de la escasa presencia de los deportes de lucha con agarre en las clases de educación física en la ESO. Propuesta de aplicación. Retos: Nuevas Tendencias en Educación Física Deporte y Recreación, 14, 43-47.

Robles, J., Abad, M., Castillo, E., Giménez, F., \& Robles, A. (2013). Factores que condicionan la presencia de la expresión corporal en la enseñanza secundaria según el profesorado de educación física. Retos: Nuevas Tendencias en Educación Física, Deporte y Recreación, 24, 171-175.

Robles, J., Fuentes-Guerra, F.J., \& Abad, M., (2010). Motivos que llevan a los profesores de educación física a elegir los contenidos deportivos en la E.S.O. Retos: Nuevas Tendencias en Educación Física, Deporte y Recreación, 18, 5-8.

Romero-Martín, M.R., Gelpi, P., Mateu, M., \& Lavega, P.
(2017). Influencia de las prácticas motrices sobre el estado emocional de estudiantes universitarios. Revista International de Medicina y Ciencias de la Actividad Física y del Deporte, 17(67), 449-466.

Sotoca, P. Arévalo, M., \& Álvarez, J. (2017). De lo viral a lo vital: un nuevo \#challenge para educación física. EmásF Revista Digital de Educación Física, 45, 93-104.

Shimelmitz, R., Kuhn, S. L., Jelinek, A.J., Ronen, A., Clark, A.E., \& Weinstein-Evron, M. (2014). 'Fire at will': the emergence of habitual fire use 350,000 years ago. Journal of Human Evolution, 77, 196-203.

Singh, A., Uijtdewilligen, L., Twisk, J.W., Van Mechelen, W., \& Chinapaw, M.J. (2012). Physical activity and performance at school: a systematic review of the literature including a methodological quality assessment. Archives of pediatrics \& adolescent medicine, 166(1), 49-55.

Skoyles, J.R. (2000). Gesture, language origins, and right handedness. Psycoloquy, 11(24).

Strong, W.B., Malina, R.M., Blimke, C.J., Daniels, S.R., Dishman, R.K., Gutin, B., et al. (2005). Evidence based physical activity for school-age youth. Journal of Pediatrics, 146(6), 732-737

Subires, M.P. (2012). El fenómeno del lipdub como experiencia audiovisual colaborativa en la era de la web social. Revista Comunicación, 10(1), 1610-1620.

Tejerina, I. (1994). Dramatización y teatro infantil. Madrid: Siglo XXI.

Vázquez, B. (1989). La Educación Física en la Educación Básica. Madrid: Gymnos.

Velázquez, C. (2013). Análisis de la implementación del aprendizaje cooperativo durante la escolarización obligatoria en el área de Educación Física (Tesis doctoral no publicada). Universidad de Valladolid, España.

Villada, P., \& Vizuete, M. (2002). Los fundamentos teóricodidácticos de la educación física. Madrid: Ministerio de Educación, Cultura y Deportes.

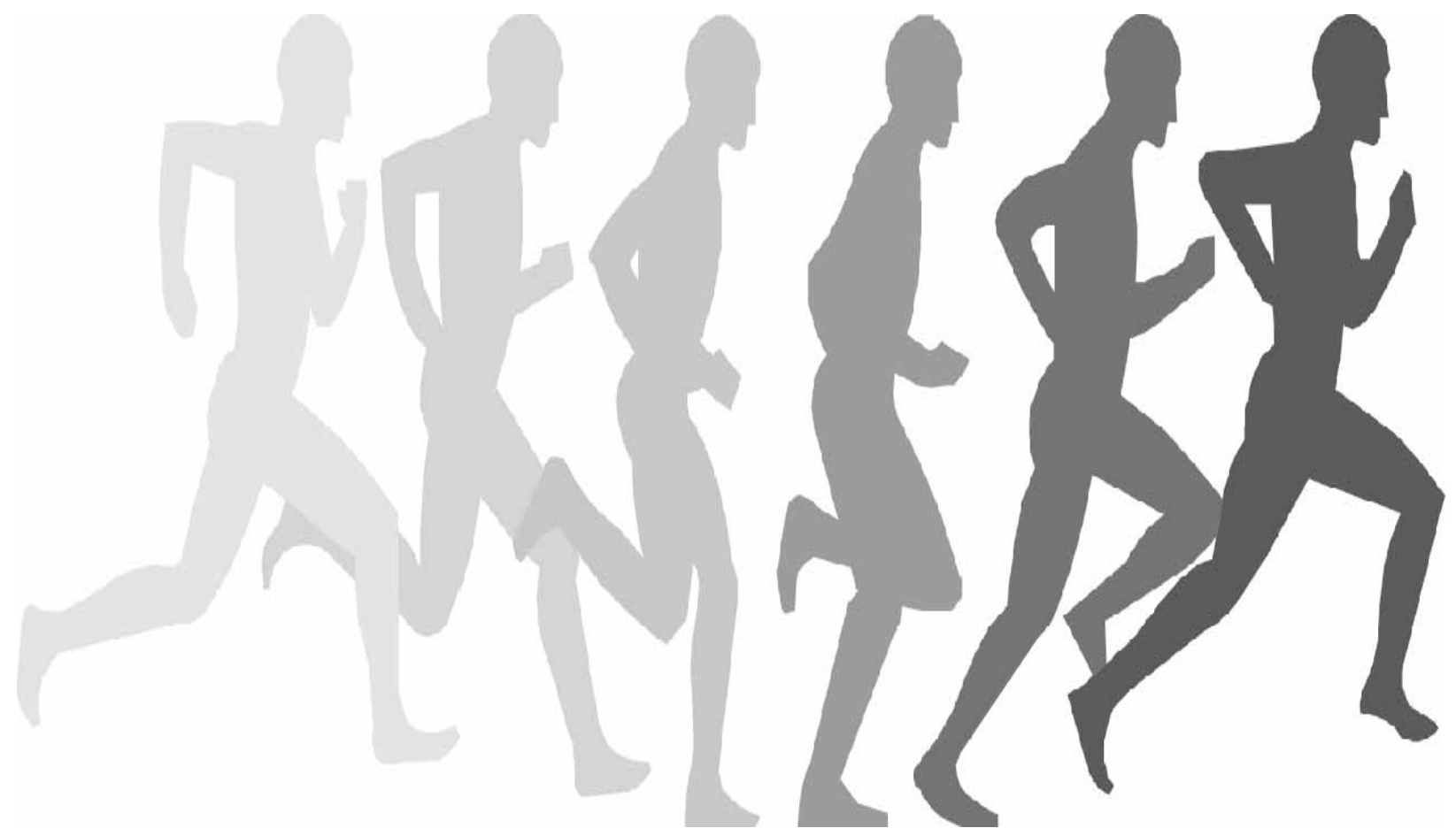

